\title{
Proliferation profile of classical Hodgkin's lymphomas. Increased expression of the protein cyclin D2 in Hodgkin's and Reed-Sternberg cells
}

\author{
Maria Bai ${ }^{1}$, Elena Tsanou ${ }^{1}$, Niki John Agnantis $^{1}$, Sevasti Kamina ${ }^{1}$, Constantina Grepi ${ }^{1}$, \\ Kalliopi Stefanaki ${ }^{2}$, Dimitra Rontogianni ${ }^{3}$, Vassiliki Galani ${ }^{4}$ and Panagiotis Kanavaros ${ }^{4}$ \\ ${ }^{1}$ Department of Pathology, Medical Faculty, University of Ioannina, Ioannina; ${ }^{2}$ Department of Pathology, Agia \\ Sophia Hospital, Athens; ${ }^{3}$ Department of Pathology, Evangelismos Hospital, Athens and ${ }^{4}$ Department of \\ Anatomy-Histology-Embryology, Medical Faculty, University of Ioannina, Ioannina, Greece
}

\begin{abstract}
There is accumulating evidence that Hodgkin's and Reed-Sternberg cells of classical Hodgkin's lymphomas (cHL) display multiple and concurrent alterations in different pathways and checkpoints of the cell cycle. However, the expression of cyclin D2 and its relation to other major cell cycle proteins has not been analyzed in cHL. The aim of the present study was to assess expression of cyclin D2, Ki67, cyclin A, cyclin B1, cyclin D1, cyclin D3, cyclin E, p53, Rb, p16 and p27 proteins in order to gain further insight into the proliferation profile of cHL. Overexpression of cyclin D2 in Hodgkin's and Reed-Sternberg cells was detected in 64/89 (72\%) cases of cHL. This finding, in view of recent in vitro data showing that constitutive activation of nuclear factor (NF)-kB could upregulate cyclin D2 expression in part via signal transducer and activator of transcription (STAT)-5a, suggests that induction of cyclin D2 expression may support the proliferation of Hodgkin's and Reed-Sternberg cells. In addition, the present study showed that (1) increased p27 expression status was significantly correlated with higher levels of cyclin $A$ expression $(P=0.048)$ and $(2)$ increased p53 expression status was significantly correlated with higher levels of cyclin $A(P<0.001)$ and cyclin $B 1(P=0.040)$ expression. The association between increased p27 and p53 expression status and higher expression levels of G2/M cyclins suggests that the impairment of the growth inhibitory activity of the p27 and p53 tumor suppressor pathways may promote the proliferation of Hodgkin's and Reed-Sternberg cells.
\end{abstract}

Modern Pathology (2004) 17, 1338-1345, advance online publication, 3 September 2004; doi:10.1038/modpathol.3800183

Keywords: cell cycle; Hodgkin's lymphomas

Cell cycle progression is regulated by cyclin-dependent kinases (CDK) which are activated by cyclins that bind to CDKs to form serine/threonine kinase holoenzyme complexes. ${ }^{1,2}$ Cyclins are divided in two main functional families. ${ }^{1,2}$ The G1 family includes the cyclins D1, D2, D3 and E, which are important for the passage of cells through the G1 phase and their entry into the S-phase. The other family includes the cyclins A, B1 and B2. Cyclin A is involved in DNA synthesis, S-phase completion and preparation for mitosis. Cyclins B1 and B2 control the onset, sequence of events and completion of mitosis. Cyclin-dependent kinase inhibitors

Correspondence: Dr M Bai, MD, PhD, Department of Pathology, Medical School, University of Ioannina 45110, Ioannina, Greece. E-mail: mbai@cc.uoi.gr

Received 26 February 2004; revised and accepted 26 April 2004; published online 3 September 2004
(CDKIs) regulate negatively the kinase activity of the complexes composed of cyclins and CDKs. ${ }^{1,2}$ There are two known families of CDKIs. The INK4 inhibitors (p16/INK4A, p15/INK4B, p18/INK4C and p19 (p14)/INK4D) are specific for CDK4 and 6, while the CIP/KIP inhibitors (p21/CIP1, p27/KIP1 and p57/KIP2) target CDK 2, 4 and 6.

Classical Hodgkin's lymphomas (cHL) have now been recognized as B-cell lymphomas with cases of T-cell origin being exceptional., ${ }^{3,4}$ There is accumulating evidence that Hodgkin's and Reed-Sternberg (H/RS) cells, the neoplastic-cell population in cHL, are characterized by a profound disturbance of the cell cycle and apoptosis regulation. ${ }^{4-37}$ In this respect, of particular importance is the constitutive activation of nuclear factor (NF)-kB pathway in HLcell lines and neoplastic tissues, which is considered to be involved in the proliferation and survival of H/RS cells. ${ }^{4,12-16}$ A number of studies reported 
that H/RS cells display aberrant cell cycle features such as S-phase disorder, frequent aneuploidy and abortive mitoses with arrest at the metaphase-ana/ telophase transition leading to the formation of characteristic multinucleated cells and/or cell deletion. ${ }^{5-11}$ Additional studies provided evidence that cell cycle deregulation in cHL may result from alterations of the p53 (p14-Hdm2-p53-p21), Rb (p16-cyclin D-CDK4-Rb) and p27 (p27-cyclin E-CDK2) tumor suppressor pathways. ${ }^{18-34}$ Furthermore, some studies showed that H/RS cells frequently overexpress cyclins involved in the G1/S and G2/M transition such as cyclins E, D3, A and B1. ${ }^{11,26,29,33,35-37}$ However, the immunohistochemical expression of cyclin D2 and its relation to other major cell cycle proteins has not been analyzed in cHL. This could be of interest since recent in vitro data showed that constitutive activation of NF-kB could upregulate cyclin D2 expression in part via signal transducer and activator of transcription (STAT) 5a. ${ }^{15}$ Therefore, the expression of cyclin D2 and its relation to other cell cycle proteins (Ki67 and cyclins A, B1, D1, D3 and E) were analyzed by immunohistochemistry in order to gain further insight into the proliferation profile of cHL. In addition, these proteins were studied in relation to the p53, Rb, p16 and p27 expression status because alterations of the $\mathrm{p} 53, \mathrm{Rb} / \mathrm{p} 16$ and $\mathrm{p} 27$ pathways have been associated with increased expression of G1/S and G2/M cyclins in diffuse large B-cell lymphomas (DLBCL) and Burkitt's lymphomas. ${ }^{38-40}$

\section{Materials and methods}

\section{Material}

In all, 103 cases of cHL (69 nodular sclerosis and 34 mixed cellularity) classified according to the World Health Organization classification ${ }^{41,42}$ were selected from the files of the Departments of Pathology of the University of Ioannina, Agia Sophia Hospital of Athens and Evangelismos Hospital of Athens on the basis that sufficient formalin-fixed, paraffinembedded tissue material was available for performing multiparameter immunohistochemical analysis.

\section{Immunohistochemistry}

Immunostainings were performed on formalinfixed, paraffin-embedded tissue sections by the routine Streptavidin-Biotin Peroxidase labeled (LSAB) procedure. A step of microwave pretreatment was used as described previously. ${ }^{19}$ The following monoclonal antibodies were applied: p53 (DO-7, Dako SA, Glostrup, Denmark, dilution 1:50), Rb (Rb1, Dako SA dilution 1:50), Ki67 (MIB1, Dako SA, dilution 1:50), cyclin A (6E6, Novocastra, Newcastle upon Tyne, UK, dilution 1:50), cyclin B1 (7A9, Novocastra, dilution 1:10), cyclin D1 (DCS-6, Novocastra, dilution 1:50), cyclin D2 (DCS-3.1,
Novocastra, dilution 1:50), cyclin D3 (DCS-22, Novocastra, dilution 1:10), cyclin E (13A3, Novocastra, dilution 1:10), p16 (F-12, Santa Cruz Biotechnology, USA, dilution 1:50) and p27 (IB4, Novocastra, dilution 1:50). Positive control slides consisted of reactive lymph nodes, thymuses, Hodgkin and non-Hodgkin's lymphomas from previous studies performed by members of our group. ${ }^{19,25,28,39,40}$ The counting of immunopositive cells was performed as described previously. ${ }^{39}$ Briefly, a continuous score system was adopted by using the $\times 40$ objective lens and counting the immunopositive H/RS cells in at least 10 fields selected on the basis that they contained immunopositive H/RS cells. The expression status of the proteins in H/RS cells was determined taking into consideration previously published criteria. ${ }^{23,33,37,39}$ Overexpression of cyclins A, B1, D1, D2, D3 and E was considered when at least $10 \%$ of H/RS cells were positive. Ki67, p53, p27 and Rb increased expression was considered when at least $50 \%$ of H/RS cells were positive. p16 increased expression was considered when the expression of this protein in H/RS cells was similar to benign lymphoid cells in reactive lymphoid tissues.

\section{Statistical Analysis}

Spearman's correlation coefficient test, MannWhitney test, $\chi^{2}$-tests, $k$-means cluster analysis and discriminant analysis were applied using the program SPSS for Windows Release 10. The results were considered as statistically significant when $P<0.05$.

\section{Results}

\section{Expression Status of Various Proteins}

Overexpression of cyclin D2, cyclin A, cyclin B1, cyclin D1, cyclin D3 and cyclin E proteins in H/RS cells was found in 64/89 (72\%), 81/93 (87\%), 79/93 (84\%), 2/88 (2\%), 34/88 (39\%), 72/88 (80\%) cases, respectively (Table 1) (Figure 1). Increased expression of Ki67, p53, Rb, p16 and p27 proteins in H/RS cells was found in 64/99 (65\%), 35/101 (35\%), 37/93 (40\%), 61/89 (68\%) and 31/92 (33\%) cases, respectively (Table 1) (Figure 1).

\section{Relations between Various Proteins}

The expression levels of p53, Rb, p16, p27, Ki67 and cyclins A, B1, D2, D3 and $\mathrm{E}$ were analyzed as continuous variables by Spearman's correlation test. Significant positive correlations were found between cyclin A/p53 $(r=0.497, P<0.001)$, cyclin A/cyclin B1 $(r=0.374, P<0.001)$, cyclin A/cyclin D2 $(r=0.266, \quad P=0.016)$, cyclin A/cyclin D3 $(r=0.396, P<0.001)$ and cyclin B1/p53 $(r=0.311$, $P=0.002)$. 
The expression status (low vs increased expression) of p53, Rb, p16 and p27 was analyzed in relation to the expression levels of Ki67 and cyclins A, B1, D2, D3 and E by Mann-Whitney test. Significant positive correlations were found (a) between increased p27 expression status and higher levels of cyclin A expression $(P=0.048)$ (Table 2) and (b) between increased p53 expression status and higher levels of cyclin A $(P<0.001)$ and cyclin B1 $(P=0.040)$ (Table 3). By Mann-Whitney test the combined p27/p53 increased expression status showed significant correlation with higher levels of cyclin A $(P=0.007)$ and cyclin B1 $(P=0.003)$ expression whereas the combined $\mathrm{p} 27 / \mathrm{Rb} / \mathrm{p} 16$ or $\mathrm{p} 53 / \mathrm{Rb} / \mathrm{p} 16$ expression status (low vs increased expression) showed no significant correlation with

Table 1 Expression of cyclin D2, cyclin A, cyclin B1, cyclin D1, cyclin D3, cyclin E, Ki67, p53, Rb, p16 and p27 proteins

\begin{tabular}{lc}
\hline Proteins & Positive cases/total cases \\
\hline cyclin D2 & $64 / 89(72 \%)$ \\
cyclin A & $81 / 93(87 \%)$ \\
cyclin B1 & $79 / 93(84 \%)$ \\
cyclin D1 & $2 / 88(2 \%)$ \\
cyclin D3 & $34 / 88(39 \%)$ \\
cyclin E & $72 / 88(80 \%)$ \\
Ki67 & $64 / 99(65 \%)$ \\
P53 & $35 / 101(35 \%)$ \\
Rb & $37 / 93(40 \%)$ \\
P16 & $61 / 89(68 \%)$ \\
P27 & $31 / 92(33 \%)$ \\
\hline
\end{tabular}

the expression levels of Ki67 and cyclins A, B1, D2, D3 and E.

\section{Combined Expression Patterns of Cyclins}

The combined expression patterns are summarized in Table 4. The two cyclin D1 overexpressing cases showed concomitant cyclin D2 overexpression.

Table 2 Relations between expression status of $\mathrm{p} 27$ protein and the expression levels of Ki67, cyclin A, cyclin B1, cyclin D2, cyclin D3 and cyclin E proteins (Mann-Whitney test)

\begin{tabular}{|c|c|c|c|}
\hline Proteins & Group p27 & Number of cases & Mean rank \\
\hline \multirow[t]{2}{*}{ Ki67 } & 1 & 31 & 43.84 \\
\hline & 2 & 60 & $\begin{array}{c}47.12 \\
P=0.573\end{array}$ \\
\hline \multirow[t]{2}{*}{ cyclin A } & 1 & 29 & 51.52 \\
\hline & 2 & 58 & $\begin{array}{c}40.24 \\
P=0.048^{*}\end{array}$ \\
\hline \multirow[t]{2}{*}{ cyclin B1 } & 1 & 29 & 47.98 \\
\hline & 2 & 58 & $\begin{array}{c}42.01 \\
P=0.278\end{array}$ \\
\hline \multirow[t]{2}{*}{ cyclin D2 } & 1 & 22 & 44.25 \\
\hline & 2 & 59 & $\begin{array}{c}39.79 \\
P=0.439\end{array}$ \\
\hline \multirow[t]{2}{*}{ cyclin D3 } & 1 & 27 & 38.37 \\
\hline & 2 & 51 & $\begin{array}{c}40.10 \\
P=0.740\end{array}$ \\
\hline \multirow{2}{*}{ cyclin E } & 1 & 27 & 40.54 \\
\hline & 2 & 51 & $\begin{array}{c}38.95 \\
P=0.765\end{array}$ \\
\hline
\end{tabular}

Group 1, increased p27 expression; Group 2, low p27 expression. The asterisk indicates the statistically significant correlations.
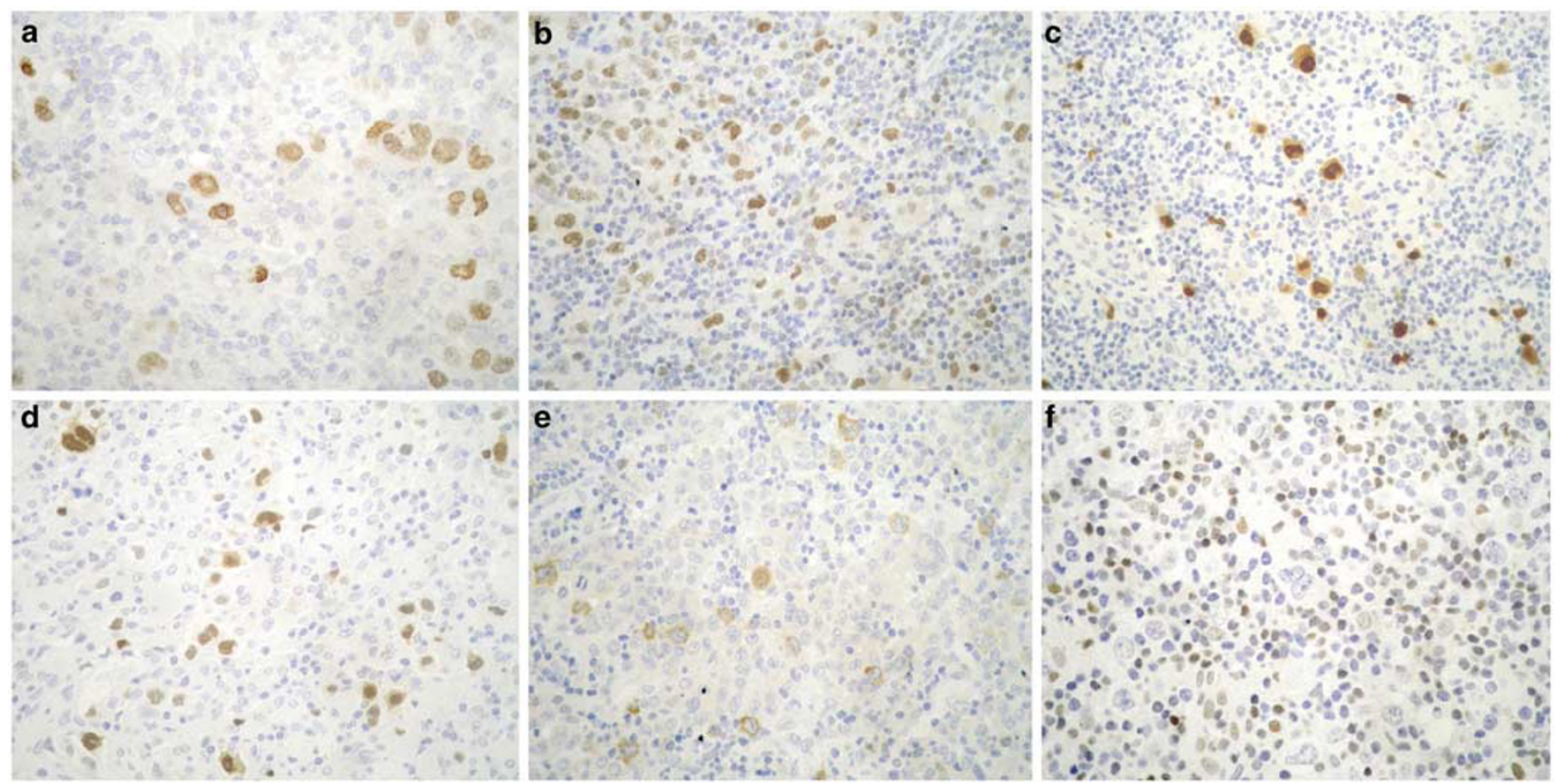

Figure 1 (a) Expression of cyclin D2, (b) cyclin D3, (c) cyclin E, (d) cyclin A, (e) cyclin B1 and (f) p27 proteins in Hodgkin's and ReedSternberg cells (magnification $\times 400$ ). 
Table 3 Relations between expression status of p53 protein and the expression levels of Ki67, cyclin A, cyclin B1, cyclin D2, cyclin D3 and cyclin E proteins (Mann-Whitney test)

\begin{tabular}{|c|c|c|c|}
\hline Proteins & Group p53 & Number of cases & Mean rank \\
\hline \multirow[t]{2}{*}{ Ki67 } & 1 & 33 & 49.38 \\
\hline & 2 & 63 & $\begin{array}{c}48.40 \\
P=0.822\end{array}$ \\
\hline \multirow{2}{*}{ cyclin A } & 1 & 31 & 61.65 \\
\hline & 2 & 62 & $\begin{array}{c}39.68 \\
P<0.001 *\end{array}$ \\
\hline \multirow{2}{*}{ cyclin B1 } & 1 & 31 & 54.84 \\
\hline & 2 & 62 & $\begin{array}{c}43.08 \\
P=0.040^{*}\end{array}$ \\
\hline \multirow[t]{2}{*}{ cyclin D2 } & 1 & 28 & 45.23 \\
\hline & 2 & 58 & $\begin{array}{c}42.66 \\
P=0.649\end{array}$ \\
\hline \multirow[t]{2}{*}{ cyclin D3 } & 1 & 31 & 47.53 \\
\hline & 2 & 53 & $\begin{array}{c}39.56 \\
P=0.130\end{array}$ \\
\hline \multirow[t]{2}{*}{ cyclin E } & 1 & 31 & 44.47 \\
\hline & 2 & 53 & $\begin{array}{c}41.35 \\
P=0.565\end{array}$ \\
\hline
\end{tabular}

Group 1, increased p53 expression; Group 2, low p53 expression. The asterisk indicates the statistically significant correlation.

Concomitant cyclin D2/D3 overexpression, mutually exclusive cyclin D2/D3 overexpression and absence of overexpression of both cyclin D2/D3 was found in 23/77 (30\%), 38/77 (50\%) and 16/77 $(20 \%)$ cases, respectively ( $\chi^{2}$-test, $\left.P=0.192\right)$. Concomitant cyclin $E / D$ (D1 or D2 or D3) overexpression, mutually exclusive cyclin E/D overexpression and absence of overexpression of both cyclin E/D was found in 51/83 (60\%), 32/83 cases $(40 \%)$ and $0 /$ 83 cases, respectively. There was a significant tendency for concomitant cyclin E/D (D1 or D2 or D3) overexpression ( $\chi^{2}$-test, $P=0.030$ ). Concomitant cyclin $A / B 1$ overexpression, mutually exclusive cyclin A/B1 overexpression and absence of overexpression of both cyclin A/B1 was found in 72/93 (77\%), 16/93 (17\%) and 5/93 (6\%) cases, respectively. There was a significant tendency for concomitant cyclin A/B1 overexpression $\left(\chi^{2}\right.$-test, $P=0.016)$.

\section{Cluster Analysis of the Proliferation-Associated Proteins Ki67, Cyclin A and Cyclin B1}

The combined entry of the values counted for Ki67, cyclin A and cyclin B1 expression levels
Table 5 Cluster analysis of the expression levels of the proliferation-associated proteins Ki67, cyclin A and cyclin B1

\begin{tabular}{lcl}
\hline Proteins & Number of cases & Mean value \pm s.d \\
\hline Ki67 & $36(\mathrm{HP})$ & $66.11 \% \pm 16.08$ \\
& $57(\mathrm{LP})$ & $49.82 \% \pm 18.44$ \\
Cyclin A & $36(\mathrm{HP})$ & $42.36 \% \pm 15.14$ \\
& $57(\mathrm{LP})$ & $13.91 \% \pm 7.88$ \\
Cyclin B1 & $36(\mathrm{HP})$ & $25.36 \% \pm 17.43$ \\
& $57(\mathrm{LP})$ & $14.70 \% \pm 13.00$
\end{tabular}

$\mathrm{N}$, number of cases; LP, cluster of low proliferation; HP, cluster of high proliferation.

(these proteins were chosen because they were detectable in all studied cases) into a $k$-means cluster analysis ${ }^{40}$ separated the entire cohort into two clusters: a cluster of low proliferation consisting of 57 cases with simultaneous low expression levels of Ki67, cyclin A and cyclin B1 and a cluster of high proliferation consisting of 36 cases with simultaneous high expression levels of Ki67, cyclin A and cyclin B1 (Table 5). Using analysis of variance the two-cluster mean values were significantly different with respect to Ki67 $(F$-value $=18.951, \quad P<0.001)$, cyclin A $(F$-value $=141.199, \quad P<0.001) \quad$ and $\quad$ cyclin B1 $(F$-value $=11.951, \quad P=0.001) . \quad$ Using multiple analysis of variance between the cluster (low vs high proliferation cluster) as the independent variable and all three variables (Ki67, cyclin A and cyclin B1) simultaneously as the dependent vector a Wilks' lamda of $0.266(F$-value $=81.919)$ was produced $(P<0.001)$. Discriminant analysis was applied to determine which of the individual parameters (Ki67, cyclin A and cyclin B1) is closest to the results of the cluster analysis in its capacity to distinguish between low and high proliferation clusters. The decreasing order of discriminant power in this respect was as follows: cyclin A: (Wilks' lamda $=0.392$, $P<0.001)>$ Ki67: $\quad$ (Wilks' $\quad$ lamda $=0.828$, $P<0.001)>$ cyclin $\quad$ B1: (Wilks' lamda $=0.884$, $P=0.001)$. Thus, cyclin $A$ is the most powerful parameter for discriminating between high and low proliferation cluster. The classification matrix yielded a good cluster distinction: only one case belonging to the high proliferation cluster was missclassified in the low proliferation cluster.

Table 4 Combined overexpression patterns of cyclins

\begin{tabular}{lccc}
\hline Combined patterns & $\begin{array}{c}\text { Concomitant } \\
\text { overexpression }\end{array}$ & $\begin{array}{c}\text { Mutually exclusive } \\
\text { overexpression }\end{array}$ & $\begin{array}{c}\text { Double-negative } \\
\text { overexpression }\end{array}$ \\
\hline cyclin D2/cyclin D3 & $23 / 77$ cases $(30 \%)$ & $38 / 77$ cases $(50 \%)$ & $16 / 77$ cases $(20 \%)$ \\
cyclin E/D-cyclins (D1 or D2 or D3) & $51 / 83$ cases $(60 \%)$ & $32 / 83$ cases $(40 \%)$ & $0 / 83$ cases $(0 \%)$ \\
cyclin A/cyclin B1 & $72 / 93$ cases $(77 \%)$ & $16 / 93$ cases $(17 \%)$ & $5 / 93$ cases $(6 \%)$
\end{tabular}




\section{Discussion}

The present study showed overexpression of cyclin D2 in H/RS cells in 64/89 (72\%) cases of cHL. In previous reports, cyclin D2 has been studied in only 12 cases of cHL with expression identified in 5-20\% of H/RS cells. ${ }^{36}$ Therefore, our findings in the present large series of cHL are noteworthy since cyclin D2 expression is low in reactive lymph nodes, most B-cell malignancies and most malignant B-cell lines. ${ }^{36,38,43}$ Indeed, germinal center cells in reactive lymph nodes were cyclin D2 negative and the majority of cyclin D2-positive cells in the interfollicular areas were CD3-positive $\mathrm{T}$ cells whereas the CD79a-positive B cells were cyclin D2 negative. ${ }^{36}$ However, increased cyclin D2 expression was reported in monocytoid B cells in lymph nodes. ${ }^{44}$ Expression of cyclin D2 protein was absent in follicular lymphomas ${ }^{36,45}$ and present in a small percentage of DLBCL (19/152 cases) ${ }^{45}$ In contrast, most B-cell chronic lymphocytic leukemias (29/34 cases) and lymphoplasmacytic lymphomas (7/7 cases) and a part of precursor B-cell acute lymphoblastic leukemias (5/9 cases) expressed high levels of cyclin D2 mRNA. ${ }^{43,46}$ The overexpression of cyclin D2 in cHL tissue specimens may be related to recent in vitro findings showing upregulated cyclin D2 expression in cultivated H/RS cells. ${ }^{13,15,16}$ It was suggested that constitutive activation of NF$\mathrm{kB}$ can upregulate cyclin $\mathrm{D} 2$ expression in part via signal transducer and activator of transcription (STAT) 5a. ${ }^{15}$ NF-kB interferes with the Janus kinase/STAT signalling pathway and causes high levels of constitutive STAT5a activity in cultured H/ RS cells. ${ }^{15}$ In addition, nuclear expression of STAT5a, which implies constitutive STAT5a activity, was detected by immunohistochemistry in most H/RS cells in all 24 tested cases of cHL. ${ }^{15}$ The effect of STAT5a on cyclin D2 can be related to the finding that the cyclin D2 promotor contains STAT5a binding site. ${ }^{47}$ Furthermore, constitutive activation of activator protein (AP)-1, which was reported to be a constant feature of H/RS cells, could upregulate, in cooperation with NF-kB, the expression of cyclin D2 in H/RS cell lines. ${ }^{16}$ This can be related to the findings that the cyclin D2 promotor contains AP-1 and NF-kB binding sites. ${ }^{48}$ The above findings, taken together, suggest that induction of cyclin D2 expression is likely to support the proliferation of H/RS cells in most cHL. On the other hand, about $28 \%$ of cHL in the present study displayed low levels or absence of cyclin D2 expression in H/RS cells. This could be due, at least partially, to defects or absence of activation of the NF-kB pathway. Indeed, a recent study by using immunohistochemistry reported low levels or absence of the active NF-kB nuclear protein in H/RS cells in 61/257 cases (23\%) of $\mathrm{CHL} .{ }^{33}$

The present findings are in keeping with previous observations that H/RS cells in a large proportion of $\mathrm{CHL}$ are characterized by the overexpression of G1/S and G2/M cyclins such as cyclins E, A and B1 whereas overexpression of cyclin D3 is less frequent and overexpression of cyclin D1 is rather uncommon in most studies. ${ }^{11,26,29,33,35-37}$ Of particular interest is the striking overexpression of cyclin $\mathrm{E},{ }^{33,37}$ which may be involved in the pathogenesis of cHL since deregulated cyclin E expression increases chromosomal instability and polyploidy and high cyclin E expression maintains CDK2 activity whose downregulation is important for exit from mitosis. ${ }^{49,50}$ To gain further insight in the proliferation profile of cHL, we analyzed the combined overexpression patterns of G1/S and G2/M cyclins. With respect to G1/S cyclins, we observed mutually exclusive cyclin D2/D3 overexpression in $50 \%$ of cHL. This can be paralleled to the findings that cyclin D3 expression was reduced in lymphoid malignancies with cyclin D1 or D2 overexpression. ${ }^{43,51}$ Our findings suggest functional redudancy among D-type cyclins in a part of cHL. This could be supported by the observations that cyclin D3 compensates for loss of cyclin D2 in B-lymphocytes activated via the antigen receptor and CD40. ${ }^{52}$ In addition, we found a significant tendency for concomitant cyclin E/D (D1 or D2 or D3) overexpression in cHL. This suggests that in most cHL cyclin $\mathrm{E}$ was not overexpressed to substitute a putative lack of D-type cyclin expression. ${ }^{53}$ With respect to G2/M cyclins, we observed a significant tendency for concomitant cyclin $A / B 1$ overexpression in cHL. These findings could, at least partially, explain the abortive mitoses of H/RS cells ${ }^{7}$ since cyclin A can delay chromosome alignment and anaphase ${ }^{54}$ and the cyclin B1/cdk1 complex (mitosis promoting factor) is involved in chromosome condensation, nuclear membrane breakdown and mitotic spindle formation. ${ }^{55}$ Furthermore, we evaluated by cluster analysis the combined expression levels of Ki67, cyclin A and cyclin B1. Two distinct clusters of low and high proliferation profile were identified, indicating that groups with distinct cellular proliferation properties of H/RS cells can be defined in cHL. This is in keeping with the identification of two distinct clusters of kinetic event index (mitotic index + DNA fragmentation index) in cHL. ${ }^{8}$ The definition of groups with distinct cellular kinetic properties might be useful for the identification of subsets of cHL with different prognosis since the proliferation and the apoptosis status may influence the clinical behavior of these lymphomas. ${ }^{21,22,33,34,56}$

In the present study, the relations between expression levels of cyclins and expression status of p53, Rb, p16 and p27 proteins were analyzed. We observed an association between increased p53 expression status in H/RS cells and higher levels of cyclin A and cyclin B1 expression. This is in keeping with previous findings that high p53 expression in H/RS cells was associated with high 
MIB1, cyclin B1, cyclin E and CDK6 expression. ${ }^{33}$ The above findings, taken together, indicate that overexpressed $p 53$ protein in H/RS cells is unable to induce cell cycle arrest. This could be explained, at least partially, by the observation that overexpressed p53 protein is bound and inactivated by the overexpressed Hdm2 protein $^{31}$ thereby impairing the ability of $p 53$ to induce the expression of $p 53$ transactivated genes involved in G1/S and G2/M checkpoints. ${ }^{1,2,55}$ With respect to the G2/M checkpoint, p53 reduces the expression of cyclin B1 and cdk1 by repression of their promoters. ${ }^{57,58}$ Furthermore, p53 transcriptionally upregulates the expression of $14-3-3 \sigma$ which modulates the subcellular localization of cyclin B1/cdk1 complexes, as the binding of 14-3-3 $\sigma$ to cdk1 results in retention of the kinase in the cytoplasm. ${ }^{55,57}$ Thus, $p 53$ inactivation could, at least partially, explain the cyclin B1/cdk1 overexpression and the disturbed nuclear localization of Mitosis Promoting Factor components (cyclin B1 and cdk1), which are both features of H/RS cells. ${ }^{11,33}$ We also observed an association between increased p27 expression status in H/RS cells and higher levels of cyclin A expression. This is unexpected since increased levels of p27 can disrupt the cyclinE/CDK2-p107/DP1/E2F complexes, the formation of which results in transcriptional activation of cyclin A gene expression. ${ }^{59}$ Our results are in keeping with previous findings that high p27 expression is associated with high cyclin E, CDK2 and CDK6 expression in H/RS cells. ${ }^{33}$ The association between high p27 expression and high expression of proliferation-associated proteins suggests aberrant p27 expression in cHL because normal cycling lymphoid cells have very low levels of p27 protein. ${ }^{38}$ The aberrant increased p27 expression in H/RS cells might be due to p27 inactivation because of binding to D-type cyclins. ${ }^{38,60,61}$ In this respect, concomitant high p27/cyclin D3 expression in a subset of DLBCL and Burkitt's lymphomas with high growth fraction was associated with p27cyclin D3 nuclear colocalization in lymphoma cells as detected by confocal laser microscopy. ${ }^{38}$ It was suggested that p27 might be sequestered in cyclin D3/CDK4 complexes and, in this context, p27 might be protected from CDK2-mediated degradation. ${ }^{38}$ Although individual cases in the present study showed concomitant increased p27/cyclin D3 or D2/Ki67 expression, confocal laser microscopy studies are required to gain further insight into the relations between p27 and D-type cyclins in H/RS cells.

We additionally observed that combined p27/p53 increased expression status was significantly correlated with higher levels of cyclin A and cyclin B1 expression. This can be paralleled to previous observations that combined aberrations of the $\mathrm{p} 27 / \mathrm{p} 53 / \mathrm{Rb} / \mathrm{p} 16$ expression status are associated with increased expression of proliferation-associated proteins in diffuse large B-cell lymphomas. ${ }^{17,39,40}$ Our findings suggest that the combined impairment of the p27 and p53 tumor suppressor pathways exerts a cooperative effect resulting in enhanced proliferation of H/RS cells.

\section{Acknowledgements}

This study was supported in part by the grant ELE II/2000 from the Research Comission of the University of Ioannina. We are grateful to Antigoni Christodoulou for their excellent technical assistance.

\section{References}

1 Sherr CJ. The Pezcoller lecture: cancer cell cycles revisited. Cancer Res 2000;60:3689-3695.

2 Malumbres M, Barbacid M. To cycle or not to cycle: a critical decision in cancer. Nat Rev Cancer 2001; 1:222-231.

3 Pileri SA, Ascani S, Leoncini L, et al. Hodgkin's lymphoma: the pathologist's viewpoint. J Clin Pathol 2001;55:162-176.

4 Thomas RK, Re D, Wolf J, et al. Part I: Hodgkin's lymphoma-molecular biology of Hodgkin and Reed-Sternberg cells. Lancet Oncol 2004;5:11-18.

5 Erdkamp FL, Schouten HC, Breed WP, et al. DNA aneuploidy in Hodgkin's disease: a multiparameter flow cytometric analysis. Leuk Lymphoma 1994;12: 297-306.

6 Weber-Matthiesen K, Deerberg J, Poetsch M, et al. Numerical chromosome aberrations are present within the CD30+ Hodgkin and Reed-Sternberg cells in 100\% of analyzed cases of Hodgkin's disease. Blood 1995; 86:1464-1468.

7 Leoncini L, Spina D, Close P, et al. Abortive mitoses and nuclear DNA fragmentation in CD30+ large cells of Hodgkin's disease. Leuk Lymphoma 1995;22:119-124.

8 Spina D, Leoncini L, Close P, et al. Growth vs DNA strand breaks in Hodgkin's disease: impaired proliferative ability of Hodgkin and Reed-Sternberg cells. Int J Cancer 1996;66:179-183.

9 Leoncini L, Spina D, Close P, et al. Mitotic activity and nuclear DNA damage of large cells in Hodgkin's disease: comparison with the expression of p53 and bcl-2 proteins and the presence of Epstein-Barr virus. Leuk Lymphoma 1997;25:153-161.

10 Leoncini L, Spina D, Megha T, et al. Cell kinetics, morphology, and molecular IgVH gene rearrangements in Hodgkin's disease. Leuk Lymphoma 1997;26: 307-316.

11 Leoncini L, Megha T, Lazzi S, et al. Cellular kinetic differences between Hodgkin's disease and anaplastic large cell lymphomas: relation to the expression of p34cdc2 and cyclins B1. Int J Cancer 1998;29:408-414.

12 Bargou RC, Emmerich F, Krappmann D, et al. Constitutive nuclear factor-kappaB-ReIA activation is required for proliferation and survival of Hodgkin's disease tumor cells. J Clin Invest 1997;100:2961-2969.

13 Hinz M, Loser P, Mathas S, et al. Constitutive NFkappa B maintains high expression of a characteristic gene network, including CD40, CD86 and a set of 
antiapoptotic genes in Hodgkin/Reed-Sternberg cells. Blood 2001;97:2798-2807.

14 Izban KF, Ergin M, Huang Q, et al. Characterization of nf-kappab expression in Hodgkin's disease: inhibition of constitutively expressed nf-kappab results in spontaneous caspase-independent apoptosis in Hodgkin and Reed-Sternberg cells. Mod Pathol 2001;14: 297-310.

15 Hinz M, Lemke P, Anagnostopoulos I, et al. Nuclear factor kappaB-dependent gene expression profiling of Hodgkin's disease tumor cells, pathogenetic significance and link to constitutive signal transducer and activator of transcription 5a activity. J Exp Med 2002; 196:605-617.

16 Mathas S, Hinz M, Anagnostopoulos I, et al. Aberrantly expressed c-Jun and JunB are a hallmark of Hodgkin lymphoma cells, stimulate proliferation and synergize with NF-kappa B. EMBO J 2002;21:4104-4113.

17 Sanchez-Beato M, Sanchez-Aguilera A, Piris MA. Cell cycle deregulation in B-cell lymphomas. Blood 2003;101:1220-1235.

18 Sanchez-Beato M, Piris MA, Martinez-Montero JC, et al. Mdm2 and p21 WAF1/CIP1, wild-type p53-induced proteins, are regularly expressed by Reed-Sternberg cells in Hodgkin's disease. J Pathol 1996;180:58-64.

19 Tzardi M, Kouvidou C, Panagiotides I, et al. Expression of p53 and mdm2 proteins in Hodgkin's disease. Absence of correlation with the presence of EpsteinBarr virus. Anticancer Res 1996;16:2813-2820.

20 Lorenzen J, Thile J, Fischer R. The mummified Hodgkin cell: cell death in Hodgkin's disease. J Pathol 1997;182:288-298.

21 Morente MM, Piris MA, Abraira V, et al. Adverse clinical outcome in Hodgkin's disease is associated with loss of retinoblastoma protein expression high Ki67 proliferation index and absence of Epstein-Barr virus latent membrane protein 1 expression. Blood 1997;80:2429-2436.

22 Naresh KN, O’Connor G, Soman C, et al. A study of p53 protein, proliferation cell nuclear antigen and p21 in Hodgkin's disease at presentation and at relapse. Hum Pathol 1997;28:549-555.

23 Brink AA, Oudejans JJ, van den Brule AJ, et al. Low p53 and high bcl2 expression in Reed-Sternberg cells predicts poor clinical outcome for Hodgkin's disease: involvement in apoptosis resistance. Mod Pathol 1998;11:376-383.

24 Garcia JF, Villuendas R, Algara P, et al. Loss of p16 protein expression associated with methylation of the p16INK4A gene is a frequent finding in Hodgkin's disease. Lab Invest 1999;79:1453-1459.

25 Guenova M, Rassidakis GZ, Gorgoulis VG, et al. p16/ INK4A is regularly expressed in Hodgkin's disease: comparison with retinoblastoma, p53 and MDM2 protein status, and the presence of Epstein-Barr Virus. Mod Pathol 1999;12:1062-1071.

26 Ohshima K, Haraoka S, Fujiki T, et al. Expressions of cyclin E, A, and B1 in Hodgkin and Reed-Sternberg cells: not suppressed by cyclin-dependent kinase inhibitor p21 expression. Pathol Int 1999;49: 506-512.

27 Lauritzen AF, Moller PH, Nedergaard T, et al. Apoptosis related genes and proteins in Hodgkin's disease. APMIS 1999;107:636-644.

28 Kanavaros $\mathrm{P}$, Stefanaki K, Vlachonikolis J, et al. Expression of p53, p21/waf-1, bcl-2, bax, Rb and
Ki-67 proteins in Hodgkin's lymphomas. Histol Histopathol 2000;15:445-453.

29 Kolar Z, Flavell JR, Ehrman J, et al. Apoptosis in malignant cells in Hodgkin's disase is related to expression of the cdk inhibitor p27KIP1. J Pathol 2000;190:604-612.

30 Garcia JF, Villuendas R, Sanchez-Beato $\mathrm{M}$, et al. Nucleolar p14 (ARF) overexpression in Reed-Sternberg cells in Hodgkin's lymphoma: absence of p14 (ARF)/Hdm2 complexes is associated with expression of alternatively spliced Hdm2 transcripts. Am J Pathol 2002;160:569-578.

31 Garcia MJ, Martinez-Delgado B, Cebrian A, et al. Different incidence and pattern of p15INK4b and p16INK4a promoter region hypermethylation in Hodgkin's and CD30-positive non-Hodgkin's lymphomas. Am J Pathol 2002;161:1007-1013.

32 Sanchez-Aguilera A, Delgado J, Camacho FI, et al. Silencing of the p18INK4c gene by promoter hypermethylation in Reed-Sternberg cells in Hodgkin lymphomas. Blood [prepublished online 2003-072356].

33 Garcia JF, Camacho FI, Morente M, et al. Hodgkin and Reed-Sternberg cells harbor alterations in the major tumor suppressor pathways and cell-cycle checkpoints: analyses using tissue microarrays. Blood 2003;101:681-689.

34 Devilard E, Bertucci F, Trempat P, et al. Gene expression profiling defines molecular subtypes of classical Hodgkin's disease. Oncogene 2002; 21: 3095-3102.

35 Doglioni C, Chiarelli C, Macri E, et al. Cyclin D3 expression in normal, reactive and neoplastic tissues. J Pathol 1998;185:159-166.

36 Teramoto N, Pokrovskaja K, Szekely L, et al. Expression of cyclin D2 and D3 in lymphoid lesions. Int J Cancer 1999;81:543-550.

37 Tzankov A, Zimpfer A, Lugli A, et al. High-throughput tissue microarray analysis of G1-cyclin alterations in classical Hodgkin's lymphoma indicates overexpression of cyclin E1. J Pathol 2003;199:201-207.

38 Sanchez-Beato M, Camacho FI, Martinez-Montero JC, et al. Anomalous high p27/KIP1 expression in a subset of aggressive B-cell lymphomas is associated with cyclin D3 overexpression and P27/KIP1-cyclin D3 colocalization in tumor cells. Blood 1999;94: 765-772.

39 Bai M, Vlachonikolis J, Agnantis NJ, et al. Low expression of p27 protein combined with altered p53 and $\mathrm{Rb} / \mathrm{p} 16$ expression status is associated with increased expression of cyclin A and cyclin B1 in diffuse large B-cell lymphomas. Mod Pathol 2001; 14:1105-1113.

40 Bai M, Tsanou E, Agnantis NJ, et al. Expression of cyclin D3 and cyclin E and identification of distinct clusters of proliferative activity and apoptosis status in diffuse large B-cell lymphomas. Histol Histopathol 2003;18:449-457.

41 Harris NL. Hodgkin's disease: classification and differential diagnosis. Mod Pathol 1999;12:159-175.

42 Stein H, Delsol G, Pileri S. Classical Hodgkin's lymphoma. In: Jaffe ES, Harris NL, Stein H, Vardiman JW (eds). World Health Organization Classification of Tumours. Pathology and Genetics of Tumours of the Haematopoietic and Lymphoid Tissues. Lyon, International Agency for Research on Cancer (IARC) Press, 2001, pp 244-253. 
43 Suzuki R, Kuroda H, Komatsu H, et al. Selective usage of D-type cyclins in lymphoid malignancies. Leukemia 1999;13:1335-1342.

44 Camacho FI, Garcia JF, Sanchez-Verde L, et al. Unique phenotypic profile of monocytoid B-cells: differences in comparison with the phenotypic profile observed in marginal zone B-cells and so-called monocytoid B cell lymphoma. Am J Pathol 2001;158:1363-1369.

45 Hans CP, Weisenburger DD, Greiner TC, et al. Confirmation of the molecular classification of diffuse large B-cell lymphoma by immunohistochemistry using a tissue microarray. Blood 2003;103:275-282.

46 Delmer A, Ajchenbaum-Cymbalista F, Tang R, et al. Overexpression of cyclin D2 in chronic B-cell malignancies. Blood 1995;85:2870-2876.

47 Martino A, Holmes JH, Lord JD, et al. Stat5 and Sp1 regulate transcription of the cyclin $\mathrm{D} 2$ gene in response to IL-2. J Immunol 2001;166:1723-1729.

48 Brooks AR, Shiffman D, Chan CS, et al. Functional analysis of the human cyclin D2 and cyclin D3 promoters. J Biol Chem 1996;271:9090-9099.

49 Spruck CH, Won KA, Reed SI. Deregulated cyclin E induces chromosome instability. Nature 1999;401: 297-300.

50 D’Angiolella V, Costanzo V, Gottesman ME, et al. Role for cyclin-dependent kinase 2 in mitosis exit. Curr Biol 2001;11:1221-1226.

51 Ott M, Bartkova J, Bartek J, et al. Cyclin D1 expression in mantle cell lymphoma is accompanied by downregulation of cyclin D3 and is not related to the proliferative activity. Blood 1997;90:3154-3159.

52 Lam EWF, Glassford J, Banerji L, et al. Cyclin D3 compensates for loss of cyclin D2 in mouse B- lymphocytes activated via the antigen receptor and CD40. J Biol Chem 2000;275:3479-3484.

53 Bartek J, Lukas J. Pathways governing the G1/S transition and their response to DNA damage. FEBS Lett 2000;490:117-122.

54 Den Eltzen N, Pines J. Cyclin A is destroyed in prometaphase and can delay chromosome alignment and anaphase. J Cell Biol 2001;153:121-136.

55 Smits V, Medema R. Checking out the G2/M transition. Biochem Biophys Acta 2001;1519:1-12.

56 Abele MC, Valente G, Kerim S, et al. Significance of cell proliferation index in assessing histological prognostic categories in Hodgkin's disease. An immunohistochemical study with Ki67 and MIB-1 monoclonal antibodies. Haematologica 1997;82:281-285.

57 Taylor WR, Deprimo SE, Agarwal A, et al. Mechanisms of G2 arrest in response to overexpression of p53. Mol Biol Cell 1999;10:3607-3622.

58 Innocente SA, Abrahamson JLA, Cogswell JP, et al. P53 regulates a G2 checkpoint through cyclin B1. Proc Natl Acad Sci USA 1999;96:2147-2152.

59 Zerfass-Thome K, Schultze A, Zwerschkew W, et al. P27/KIP1 blocks cyclin E-dependent transactivation of cyclin A gene expression. Mol Cell Biol 1997;17: 407-415.

60 Lin Z, Lim S, Lim MS. Growth regulation by p27/Kip1 is abrogated by multiple mechanisms in aggressive malignant lymphomas. $\mathrm{Br} \mathrm{J}$ Haematol 2003;121: 739-748.

61 Philipp-Staheli J, Payne SR, Kemp CJ. p27(Kip1): regulation and function of a haploinsufficient tumor suppressor and its misregulation in cancer. Exp Cell Res 2001;264:148-168. 